\title{
Identity as a Resource of Development Policy in Agricultural Areas*
}

\author{
Inna Miroshnichenko \\ Kuban State University \\ Krasnodar, Russian Federation \\ E-mail: mirinna78@mail.ru
}

\author{
Elena Morozova \\ Kuban State University \\ Krasnodar, Russian Federation \\ E-mail: morozova_e@inbox.ru
}

\author{
Konstantin Getmantsev \\ Kuban State University \\ Krasnodar, Russian Federation \\ E-mail: kot34@mail.ru
}

\begin{abstract}
The aim of the study is to substantiate the importance of such a non-material resource as local identity for the development of rural local communities. The theoretical basis of the work was the concepts of local communities and the idea of responsible development voiced by I.S. Semenenko. The main methodological design of this project is an identifier approach that allows interpreting sociopolitical and socio-economic changes in terms of identity transformation and identification processes. The empirical research technique was based on a combination of such methods as focus group discussion and expert survey. The methodology of projective drawing was integrated into the sociological tools of the focus group. As a result of the empirical study, several types of local identity were identified that have the resource potential for the development of rural territories of the Krasnodar Territory. The analysis of the three case studies of rural local communities showed that there is a diversity and uniqueness of non-material resources and ways of their conversion and integration into the socioeconomic development of rural areas, which should be laid down in strategic management decisions in local and regional policies.
\end{abstract}

Keywords-development policy; local identity; rural area; local communities; nonmaterial resources; identity politics

\section{INTRODUCTION}

Modern countries including Russia faced the challenges of rural development when the focus on agricultural and agro-industrial production and support for farming has ceased to produce tangible socio-economic results.

In socio-humanitarian knowledge, these changes were reflected in scientific discussions about the differentiation of the concepts "rural", "agricultural", "peasant", and "agrarian". Rural territories began to be understood as localities with low population density, in a certain natural

*Fund: The research was carried out within the frameworks of the grant № 19-011-31356 "Development of Rural Local Communities: the potential of identity policy under heterogeneous socio-economic and sociocultural regional space of the region", provided by RFBR. and geographical landscape, having food sources and agricultural raw materials, natural resources and a certain "non-urban" lifestyle.

In political, managerial and economic practice, a need arose to search for effective models and resources for rural development, contributing to the creation of sustainable communities of citizens interested in a new quality of life for rural residents. A fundamentally new characteristic of the policy in relation to rural territories was the achievement of a high standard of living for the rural population due to nonmaterial factors for the development of the territory, viz.the quality of the social environment and environmental relations [1].

The presented results of the research make it possible to assess the potential of local identity for the theoretical construction of models for the effective development of rural territories with a glance at their unique socio-cultural, natural-geographical landscape and institutional models of local communities, as well as to design political and managerial practices to implement these models in the face of heterogeneous socio-economic and socio-cultural space of the Russian regions.

\section{The TheORETICAL BASIS OF THE STUDY OF IDENTITY IN THE CONTEXT OF RURAL DEVELOPMENT}

The key theoretical construct of this research integrating the territory, identity and development resources, is the concept of development of local communities.

Local communities are understood as "the totality of people united by stable formal and informal ties, which are conditioned by activities within a common territory" [2]. According to this concept, rural local communities are simultaneously a subject, an object and a resource for the development of the territory, which fact is manifested in their strategic choice. 
exceeds 50 percent, in 31 subjects of the federation it is above 30 percent). Hypothetical explanations for this state of affairs can be found in the fact that rural identity is interpreted as an attribute of a departing traditional society, the study of which does not excite the imagination of political scientists. In addition, there is an underlying projection of existing social attitudes towards rural residents as "others" for townspeople ("bast shoes", "village", etc.) on the subject of research.

A wide range of rural identity studies in foreign sociology and political science confirms L.V. Smirnyagin's idea, voiced in one of his last articles [5]. Refuting the myth of the "death of space" in the era of globalization, L.V. Smirnyagin writes that the revolution in communications and transport allowed a person to build and use space in a different way - more independently from external circumstances and more focused on the needs of the person himself. The properties of the place are important not for the productive forces, but first of all for the person himself, that means a convenient living environment, historical heritage, landscaping, a society with low crime level, welcoming atmosphere.

\section{EMPIRICAL RESEARCH METHODOLOGY}

The main methodological design of this project is an identifier approach which allows interpreting socio-political and socio-economic changes in terms of identity transformation and identification processes. Considering the main vectors of the dynamics of identity in modern society, the authors relied on the European tradition of identity study associated with poststructuralism (P. Bourdieu, E. Giddens) and constructivism (P. Corcuff). The research used the approaches based on the conceptualization of identity through the analysis of collective actions (A. Melucci, C. Tilly).

The socio-cultural approach accentuates the connection of the value-subjective aspects of the macro- and micro levels of politics and the patterns of behavior of individuals, groups, communities and systems.

The political space is considered by the authors as an inter-subjective political reality. The rural "semantic" space is not the product of exclusively personal identifications of a person or the individual experience of a particular person, it is mediated by the image of the village or by the symbolic meanings of specific elements of the image reflected in the collective consciousness. This image is the result of the activity of local communities; it includes a subjective perception of the rural space, an assessment of available resources and ideas about a normative lifestyle, and acts as a social construct created and supported by the representatives of the rural community.

A field study within the framework of this project made it possible to identify and characterize the types of local identity of rural territories of the Krasnodar Territory. Municipal entities of two levels (municipal districts and settlements) acted as empirical objects. The selection of empirical field research objects (municipalities) took place in a two-stage way. At the first stage, municipalities (districts) 
of the Krasnodar Territory were selected on the basis of two criteria: 1) the achieved level of development of local communities based on the results of an integrated assessment of the potential and the vector of socio-economic development based on the taxonometric method of economic analysis; 2) the spatial division of the region into specialized economic zones (according to the Strategy of socioeconomic development of the Krasnodar Territory until 2030). According to these criteria, four municipalities were included in the first step of the selection: Timashevsky district (developing local communities with increasing rates of economic growth in the Central Economic Zone); Temryuk district (developing local communities with decreasing growth rates in the Black Sea economic zone); Krylovskoy district (regressing local communities with a slowing rate of regression in the Northern Economic Zone); Apsheron district (regressing local communities with increasing rates of regression in the Mountain economic zone).

The second stage of selection was determining those settlements within the municipality district that have polar indicators of socio-economic development. The methodology of empirical research of local identity and the identity policy of rural communities was based on a combination of such methods as focus group discussion and expert survey. A total of 8 focus group interviews were conducted in municipal areas. The sociological toolkit of the focus group integrated the methodology of the projective drawing "My village / my village in the future" to determine the "projection" of the population's ideas about the future development on the social space of the countryside and to identify the collective subjective image of the "future" countryside in its residents" eyes according to the "what was - what will be" scheme. An expert survey allowed us to verify the data obtained as a result of focus group interviews and to get expert opinion on the effectiveness of identity policies at the local level. In each municipal district, 10 experts were interviewed (40 experts in total), representing such categories as heads of local government bodies, workers of a cultural institution (museums, libraries, cultural centers), history, social studies and Kuban studies teachers, as well as representatives of municipal mass media and local business. The sociological toolkit of the expert interview was a semi-structured interview. The empirical data (transcripts) obtained as a result of focus group discussions and expert interviews were analyzed and interpreted on the basis of a qualitative strategy using polar comparison techniques that allow classification of local identities and their resource potential in the development policy of the territory.

\section{TYPES OF IDENTITY AND RESOURCES OF THE LOCAL COMMUNITIES' DEVELOPMENT OF THE KRASNODAR TERRITORY: RESULTS OF THE EMPIRICAL RESEARCH}

As a result of an empirical study, we identified several types of local identity that have a resource potential for the development of rural territories of the Krasnodar Territory.

\section{A. The Case Study "Entrepreneurship as the Basis of Local Identity" (Oktyabrskaya Rural Settlement of the Krylovskoy District)}

The October rural settlement is located in the northeastern plain part of the Kuban with an area of 311.37 square $\mathrm{km}$ and within the administrative-territorial boundaries of the local self-government unites 7 settlements: Oktyabrskaya stanitsa, farmstead Sbornyi, settlements Temp, Obil'nyi, Zaprudnyi, Kovalyovka, and Resdhetilovskii. The distance from Krasnodar to Oktyabrskaya is $160 \mathrm{~km}$. The stanitsa of Oktyabrskaya is the largest cluster in the rural settlement founded in 1870; it is located on the site of the village of Mikhailovsky, historically populated by Cossacks. Upon merging with nearby farms, the village got the name of Novomikhailovskaya. In 1963, in connection with the continuous development of both, Novomikhailovskaya and Oktyabrskaya, by the decision of the Krasnodar Territory Council of Deputies, the amalgamation was given the common name - Oktyabrskaya stanitsa. More than 13 thousand people live on the territory of the settlement and 451 small and medium-sized businesses operate mainly in the field of agricultural production (livestock, agriculture, and horticulture).

The basis of local identity is the involvement of the local population in the cultivation and sale of seedlings of fruit and ornamental plants. Almost all families that live on the territory of the village of Oktyabrskaya are involved in greenhouse and nursery activities, which in the structure of the local economy takes on the form of entrepreneurship or personal subsidiary plots. Practically all 'the community of "seedlings", according to the participants of the focus group, promote " Oktyabrskaya Saplings" not only throughout the district, but also around the Krasnodar territory. Active entrepreneurs are implementing the project "Oktyabrskaya Saplings" on the territory of their settlement, within the framework of which there is an informational and material exchange of "novelties" of plant growing, master classes in landscape design of ornamental plants, product promotion on network platforms, etc.

Marking of economic specifications can be traced in the lifestyle, natural and socio-cultural landscape of a rural settlement. The stanitsa of Oktyabrskaya is "buried" in roses and ornamental plants; stationary signboards with a list of proposed seedlings are installed in almost every household. The days of the village are accompanied by contests of landscape design of households. The main threat to a stable business community was the emergence of the" Crimeans" the "strangers" who offer lower prices and a larger variety of assortment.

A monolithic local community differentiates only in the period of active sales (spring-autumn period), when they become competitors to each other. Yet, despite the declared 8.5 thousand rubles average per capita income and 49.86 percent of the population's employment, as well as the listed infrastructure problems of the rural settlement, residents feel "safe and happy," which is confirmed not only by positive emotional identifications, but also by the quality of 
residential and non-residential buildings, roads, and social infrastructure facilities, trade and restaurant business.

The solution of issues of local importance and problems of local residents is carried out through cooperation and effective communication of business and local authorities. Partnership traditions are rooted in the Soviet past, when in the stanitsa of Oktyabrskaya there were several state farms and a large railway junction that supported objects of social infrastructure, whose management was actively involved in solving socio-economic problems of the territory. The absence of a territorially integrated socio-cultural, shopping, entertainment and symbolic center of Oktyabrskaya stanitsa is explained by the functioning on its territory of several powerful economic agents, belonging to which "zoned" the local space and differentiated the inhabitants. Representatives of the businesses are consistently recruited to the deputy corps of the settlement.

The entrepreneurial "spirit" can also be traced in the identification with significant people of the settlement, one of whom is a contemporary of the focus group participants, Konstantin Murugov, the "charitable name" of the village, Chairman of the Council of Oktyabrskaya rural settlement of the Krylovskoy district, Head of the Chamber of Mentors of the Council of Young Deputies of the Krasnodar Territory.

Thus, we can talk about the formed local community, in which the basis for local identification is the economic specialization of the population, which allows for the socioeconomic stability of the bulk of the population. The effectiveness of the administrative mechanism for the development of the territory is realized through updating the subjective position of economic agents, as well as through the formal and informal practices of interaction between business and local authorities, preserving continuity in generations of the local elite.

\section{B. The Case Study "Local Patriotic Movement as a Factor in the Integration of the Local Community" (Kurinskoye Rural Settlement of the Municipality Apsheronsk District)}

The stanitsa of Kurinskaya is the administrative center of the Kurinsky rural settlement, which also includes the Stary Kurinsky farm, the Gorodok farm, the Stantsionny village (Khadyzhensk railway station) with the total population of more than three thousand residents, with over $70 \%$ Russians, $8 \%$ Armenians and $11 \%$ Greeks. The rural settlement is located in the mountain forest zone, $14 \mathrm{~km}$ west of the city of Khadyzhensk on the Pshish River. The village of Kurinskaya was formed in 1864 as a guard post of the Cossacks of the Kurinsk infantry regiment No. 79 of the tsarist army, which was sent to subjugate the highlanders. Local identity as a common sense of involvement in the Kurinskaya local community is realized through two dominant identifications: identification with the features of the natural landscape and identification with significant historical events. The Kurinskaya rural settlement shares common borders with the Caucasian State Natural Biosphere Reserve. The natural resources of the settlement marked by the locals are valuable species of wood, berries, mushrooms, as well as spring and hydrogen sulfide healing waters. An integral part of the unique mountain-forest landscape of the rural settlement is the Orthodox Holy Spring of Elijah the Prophet, which is located near the village of Kurinskaya (behind the farm of Gorodok, on the Mount Ilya).The Orthodox monument personifies the miracle of healing of an incurable patient due to ablution in the source and collects thousands of pilgrims. On August 2, when Orthodox Christians celebrate the memory of St. Elijah the Prophet, a huge number of believers flock to the village of Kurinskaya to go along the forest road to the holy spring bearing the name of the saint. All respondents (focus group participants and experts), emphasizing the ecological attractiveness of the settlement, consider migrants from Siberia and central Russia as "strangers", and their spirit of enterprise as a "challenge" to their local community:

"If you know, in Russia the city of Khadyzhensk and its environs are considered one of the most environmentally friendly ... In Russia there are only 2 such places. For many people who want to live environmentally friendly, grow their vegetables - this is a fertile place. With us, for example, on Solnechnaya Street, they buy land there and are engaged in beekeeping. And beekeeping is so environmentally friendly ”,

"... there are more and more of them. Round houses are being built. They live by themselves ... ";

"Initially, they wanted to fit into the life of the village. They posted ads that they would show us how to drink medicinal tea. How to eat raw mushrooms. We just called the FSB officers and that's all ... ";

“... had a conversation with them, and they stopped attracting, disturbing the local population. They are very smart, competent, adequate. Come into contact easily, it is sometimes hard to communicate with them. They wanted to go to the deputies, but ... they didn't convince people, they didn't file."

At the same time, all residents note the "wild" nature of the use of natural resources: the lack of infrastructure at the Orthodox monument; illegal local history and extreme routes in demand by representatives of active tourism; "Visiting savages" at hydrogen sulfide sources, residents of the environs and guests of the Krasnodar Territory, "stocking up in cans and bottles with spring water."

The deficit of "entrepreneurial culture" is also evident in the identification of residents with transport infrastructure (the Armavir-Tuapse railway passes through the rural settlement, the Khadyzhensk railway station is located in the farm of Stantsionny, where long-distance trains and commuter trains stop, and the highway Maykop- Tuapse passes through the village.

There is a wheel in the emblem of a rural settlement as a symbol of transport routes; residents and the Head of the settlement note the contribution of the "railroad workers" to the solution of the social problems of the territory; at the same time the gastronomic infrastructure and civilized "points" of selling local products along the entire length of transport routes in the rural settlement are absent. 
"In general, it's nice to live in the settlement, because it's clean, we are improving it .... infrastructure development: a hospital and a sports complex are also being built.

In the structure of the multinational population, about $30 \%$ are representatives of the Muslim diaspora, which is also heterogeneous in its composition (Meskhetian Turks, Kurds, Yezidis, Khemshils, Azerbaijanis and others). Migration flows were determined by the need of the settlement for seasonal workers, who were involved in the agricultural activities of the settlement enterprises: "We worked here, then brought families, then relatives, of course, came, "... the people were hospitable. A man moved here they gave him a calf, milk ... all that one needs will be given, bricks will be brought. Here the population is like this... and here we are. Here we live."

The administration of the rural settlement is a team of like-minded people focused on attracting resources and involving active citizens in solving the problems of the territory: "Our Head, Ivan Matveevich loves grants ... state programs in the Territory, he probably knows them by heart. And his assistant, Alexandra Viktorovna, with whom they work all the time. They know what is being done and where and how, and what you do to improve the life of the Kuban rural settlement"; "Our goal is not to become famous, but to create normal conditions for the residents who work here ... to change life for the better in all villages of the settlement ... Regardless ... Some people reproach: Malko settlement is small, just 400 people, but they are people too. People everyone want life to change at least somehow. Because everyone has different opportunities ... We have a kind of subsidized budget. Little money, so we get out in the sense where possible. Somewhere on our own, we save budget money, somewhere we entered the program, somewhere we ask entrepreneurs. And although slowly, but we are developing step by step ... "

Focusing on the future, the team maintains continuity and draws on the experience of previous generations. A striking example is the identity of the "old-timers." Nikolai Emelyanov, 82 years old, having worked as Head of the village administration for more than 25 years, headed the Council of Veterans of the Kuban rural settlement: "He knows all the exits in the Krasnodar Territory, all the institutions." Anatoly Kovtun, 72 years old, having the experience of the people's deputy of the Supreme Council of Kyrgyzstan in the Soviet years, “... I could not help but lead an active lifestyle: 3 terms, i.e. for 15 years I was Chairman of the Council of the Kuban rural settlement. Currently, I do not want to stay away, I continue to work ...".

The symbolic space of the settlement is also indicative of the integrative plan. The basis of the historical center is the functioning Trinity Church, built in 1874, and a school built in 1910, with a modern library, a cultural center, stadiums and an outdoor stage area with a landscaped park area adjoining them. "We have a mass participation village day for the whole day. It all starts in the morning with sporting events, because so many young people and children are involved in sports. We get a church and 2 fields next to the stadium ... it all flows smoothly to the sites, there are game 
programs. We invite trampolines, trade and all the rest. The concert program is absolutely great. We invite our local dance and song and folklore teams. In the evening there are fireworks. " "A festival of national cultures is a must." "During the festival, each nation presents its own dishes and tasting takes place; recently we have added a fats contest." "Those who get to know that the Village Day is held in Kuban settlement flock there from all over the region".

The economic problems associated with the elimination of the tobacco farm, the lack of gasification did not become an obstacle to the development of the settlement. The socioeconomic development strategy proposed by the administration takes into account the resource potential of the rural settlement, including:

- horticulture, greenhouse vegetable growing, cultivation of planting material of decorative crops, meat farming;

- development of the resort and recreational industry and the expansion of the market for agricultural products;

- growing and processing of medicinal and essential oil-bearing plants (including wild ones), agricultural tourism.

The administration of the Kuban rural settlement sees the creation of new enterprises in the context of the implementation of a regional priority investment project "Reconstruction and development of a complex of logging, wood processing, production of MDF boards on the basis of the production facilities of "Apsheronsk" production. Using modern technology, enterprises will specialize in the manufacture of furniture from an array of local valuable hardwood or MDF boards produced in the Apsheronsk district.

Thus, the local identity of the residents of the Kuban rural settlement became the basis for constructing a strong local community with a civic culture of "complicity" in which the local government becomes the "designer" and "operator" of local development.

\section{CONCLUSION}

The case study of Oktyabrskaya rural settlement showed that the positive local identity of the local community with a pronounced subjective position of the business elite and entrepreneurial structures is a sustainable resource for the development of this territory. However, an empirical study showed that the resource potential of a rural settlement is much wider. For example, here belongs the museum of the scientist Yuri Vasilyevich Kondratyuk, a resident of the village, one of the pioneers of the development of the fundamentals of astronautics, whose name is rightly on a par with the names of such outstanding scientists as K.E. Tsiolkovsky, N.I. Kibalchich, F.A. Zander, S.P. Korolev. The museum named after Yu.V. Kondratyuk can enter the scientific and technical heritage of the Russian space age and the socio-cultural programs for its popularization for various target audiences.
The mythologization of the literary event "the move of Aksinya and Gregory, the heroes of M. Sholokhov's "And Quiet Flows the Don", to the village of Novomikhailovskaya (the former name of Oktyabrskaya settlement) can become the concept of a new ethnographic complex based on the traditions of the Cossacks. The full use of the resource potential of Oktyabrskaya settlement will allow the formation of sustainable "growth points" associated with the diversification of local economy. The creation of an ethnographic and museum complex in the transport and logistics hub of the Krasnodar Territory can become the basis for the increase in the added value of the local product and have a multiplier effect for rural economy (the development of the restaurant business, transportation, increased sales of local products, etc.). At the same time, the presented "Strategy for the Strategy of Social and Economic Development of Oktyabrskaya rural settlement of the Krylovskoy District for 2017-2019" does not update the local identity of the territory, including typical investment projects in the development program but ignoring unique non-material resources.

The case study of the Kurinskii rural settlement showed that the local community can be integrated, can have the experience of involving different groups of the population in the politics of memory, but it has a retrospective orientation and does not see the available resources and development prospects. Positive business practices based on eco-tourism and the production of environmentally friendly products are perceived by the population as "strange" and "obscure" (here belong, for example, direct Internet sales). Being part of the transport and logistics infrastructure of the Krasnodar Territory and Adygea, as well as a transfer point for numerous tourists, residents of the rural settlement could transform the "wild" formats of pilgrimage, active tourism and the use of healing waters into attractive products for external consumers. The Head of administration, having rich managerial experience, involved in a wide range of communications, could rally the team on the basis of a promising time orientation.

The case study of the Kuban settlement is, in fact, a description of the normative model of a local community with a positively colored pronounced local identity in combination with the attitude / directive 'orientation of the local residents to joint social and transformative activity. Being close in its potential (natural-climatic, socio-cultural, industrial and economic) to Kurinskii rural settlement, the Kuban settlement demonstrates a fundamentally different model of socio-economic development, in which nonmaterial resources, especially human and social capital, play a key role. Actually, in the Kuban settlement the model of responsible development is being implemented in practice, in which the moral guidelines of the administration team and the civil responsibility of residents are an integral component of managerial practices.

The results of our empirical research indicate the diversity and uniqueness of non-material resources and the ways of their conversion and integration into the socioeconomic development of rural areas, which should be laid 
down in strategic management decisions in local and regional policies.

\section{REFERENCES}

[1] Reutov E.V., Reutova M.N., Shavyrina I.V. The quality of the social environment and solidarity in the local community// Management in Russia and Abroad. 2016. Iss.4. P. 68.

[2] Lyska A.G. Concept of local community constructing in international academic writing // Sociological Studies. 2013. Iss.7. P.99.

[3] Semenenko I. S. Horizons of Responsible Development: from Discourse to Governance. Polis. Political Studies. 2019. Iss. 3. Pp. $7-26$.

[4] Kotkin J. The new geography: How digital revolution is reshaping the American landscape. N.Y.: Random House, 2000. 242 p.

[5] Smirnyagin, L.V. The Evolution of Space in the Course of "Space Production" // Symbolic politics / ed. O.Yu.Malinova, INION RAS. M.: 2016. P. 86-106. 